Duncan's claims that promoting physical activity and stopping smoking are of certain benefit in reducing osteoporotic fracture in unselected elderly populations.

TUAN NGUYEN

GRAEME JONES

PHILIP SAMBROOK

PAUL KELLY STEPHEN LORD JUDITH FREUND JOHN EISMAN

Garvan Institute of Medical Research,

St Vincent's Hospital,

Darlinghurst, NSW 2010

Australia

1 Beck JR, Shultz EK. The use of relative operating characteristic (ROC) curves in test performance evaluation. Arch Pathol Lab Med 1986;110:13-20.

\section{SHOs: the lost tribes}

\section{Troubled SHOs should seek counselling}

EDITOR,-At the meeting on senior house officers reported on by Luisa Dillner ${ }^{1}$ several speakers said that junior doctors were reluctant to contact the National Counselling Service for Sick Doctors for fear that their consultants or referees would hear of their difficulties. I wish to state unequivocally that the service offers a confidential and non-coercive service to doctors who seek its help. Its primary role is to help doctors in difficulty to identify their needs and find appropriate help. The service has no connection with the General Medical Council and would contact employers or seniors only at the request of the person seeking help. The main criticism directed at the service is that it has no outcome measures or performance indicators because its preoccupation with confidentiality prevents it from maintaining central records or following up those who have used the service.

Access to the national advisers or psychiatric counsellors is normally by telephone (071 935 5982). Initially no personal details are sought, but the caller is given the telephone number of an appropriate adviser. Any doctor with health problems or problems related to stress is welcome to seek help and can be assured of complete confidentiality.

SYDNEY BRANDON

Naional Counselling Service for Sick Doctors,

London NW1 4LJ

1 Dillner L. Senior house officers: the lost tribes. $B M 7$ 1993;307: 1549-51. (11 December.)

\section{Not all tribes lost}

EDrToR,-I agree with many of the points in Luisa Dillner's article on senior house officers. ${ }^{1}$ The position of senior house officers in psychiatry, however, is usually not as unfortunate as the general picture she describes.

The Royal College of Psychiatrists lays down strict criteria for training for senior house officers in psychiatry. ${ }^{2}$ All trainees who apply to take the first part of the membership examination must have completed one year's training in accredited posts. These posts are all on rotational training schemes, which usually offer three year contracts and must have a local junior doctors group with representation on the training committee that administers the scheme. Senior house officers must attend an approved course of study for the membership examination, which operates on a half day or day release basis. Induction courses for new trainees are mandatory, as are supervision, feedback, and contact with a college tutor. Many rotations allow trainees two to three weeks to familiarise themselves with psychiatry before on call duties start.

Dillner reports that Chris Bulstrode raised the issues of cross cover at the conference for senior house officers. Specialist training in psychiatry is similar to that of surgical trainees meeting the entry requirements for the surgical fellowshipthat is, the trainees complete a series of related jobs, gaining general skills related to a particular discipline such as surgery or medicine or psychiatry. Psychiatrists already cross cover a rang of psychiatric specialties such as adult, elderly, child and adolescent, and forensic psychiatry, rehabilitation; and substance misuse. Cross covering enitrely unrelated disciplines leads to bad practice with little chance of learning from supervised experience. If there are no induction courses and no in hours contact with more senior doctors in the specialty and no prospect of rotating through the specialty, cross cover exacerbates al that is worst about current training for senior house officers. I would be as unhappy at assessing an $x$ ray film of the wrist as, I suspect, an orthopaedic senior house officer with no psychiatric experience would be at assessing a patient's risk of committing suicide.

The structures put in place by the Royal College of Psychiatrists are backed up by a system of accreditation visits. The people who make these visits must include a junior doctor and have the power to take accreditation away from unsatisfactory schemes-and do so. There is also national representation for trainees of all grades in the college through the collegiate trainees committee, which sends representatives to meetings of most of the college committees, including the council Although not always perfectly implemented, the Royal College of Psychiatrists' theory and practice of providing high quality education and training for senior house officers could serve as an example to the wider profession.

STEFFAN DAVIES

Collegiate Trainees Committee,

Royal College of Psychiatrists,

London SW1X 8PG

1 Dillner L. Senior house officers: the lost tribes. $B M \mathcal{F} 1993 ; 307$ 1549-51. (11 December)

Royal College of Psychiatrists. Handbook for inceptors and trainees London: RCP, 1987.

\section{Royal colleges active on their behalf}

Edror,-Luisa Dillner draws attention to the plight of senior house officers, whom she describes as having "no one to speak for them." The Royal College of Physicians of London regularly visits hospitals to assess the suitability of senior house officer posts for general professional training and as a result, often speaks on behalf of this beleagured group.

Through its network of regional advisers and college tutors the college has done much to encourage the provision of balanced rotational training programmes for senior house officers and less successfully, to organise formal education based on an "academic half day." Slow progress here reflects largely the pressures of clinical practice but in some instances a lack of commitment amon both teachers and the taught. Educational approval by the college is necessary before a trainee can be appointed to a senior house officer post. Throughout the past 12 months the college has visited 1552 posts involved in general professional training: only 272 received educational approval for the ful five years while 993 were approved provisionally for two years pending the rearrangement of rotas or some other aspects of professional duties. Where living standards were found to be unacceptable the hospital received limited recognition for only 12 months (287), during which time conditions must be improved and the improvement confirmed by the regional adviser. As a result many hospitals have been persuaded to provide better living conditions for their trainees.

Dillner also draws attention to the practice of requiring senior house officers to provide unsupervised cover for neonatology units. Both the Royal College of Physicians and the British
Paediatric Association withhold educational approval from posts in which resident middle grade cover is not available for first year paediatric senior house officers. Enforcement of this policy has resulted in the reorganisation of paediatric services in several hospitals.

The training, accommodation, and career guidance provided for senior house officers certainly remain considerable problems in British medicine, but it is wrong to suggest that the royal colleges are inactive in this matter.

Royal College of Physicians,

BRIAN PENTECOST

London NW1 1 LE

1 Dillner L. Senior house officers: the lost tribes. $B M \mathcal{F} 1993 ; 307$ 1549-51. (11 December.)

\section{Training inadequate in paediatric resuscitation}

EDITOR,-Concern has been expressed about the standards of training of senior house officers. ${ }^{1}$ I recently completed a six month post as a senior house officer in paediatrics and neonatal care and was surprised by the lack of emphasis on resuscitation training. To see if this was the case in Britain generally I sent a questionnaire to the on call paediatric senior house officer covering the labour ward at 100 hospitals (about one third of all units in Britain) chosen randomly. I received 60 replies $(20$ from teaching hospitals).

None of the respondents had been on an advanced paediatric life support or advanced trauma life support course. The one respondent who had been encouraged to go on these courses had been unable to get time off.

Twenty one respondents had been taught before starting the job. Twenty were taught during the job, although this consisted of formal tutorials in only eight cases. Generally, teaching was provided by registrars and senior house officers were expected to learn on the job.

Forty respondents thought that training was inadequate or "very basic." Nearly all thought that a demonstration of airway management in theatre would be helpful. Although all felt confident of maintaining an airway with a bag and mask, 21 doctors did not feel confident about intubation, and 10 had had to summon help urgently during resuscitation owing to their inability to obtain an airway. Six had been the only doctor immediately available during resuscitation.

Several points are worth raising. Firstly, more senior house officers should be encouraged, and allowed time off, to go on advanced paediatric life support and advanced trauma life support courses. Secondly, they would benefit from a more formal programme of training in paediatric resuscitation at the start of their post. A study in a region of France showed that such a programme significantly reduced the incidence of the meconium aspiration syndrome. ${ }^{2}$ In the United States a national guideline states that staff trained in neonatal resuscitation should be immediately available for every delivery. ${ }^{3}$ In Britain an anaesthetist is almost always available in maternity units, but anaesthetists may not be experienced with neonates and cannot always leave the mother. The paediatric registrar, as shown by my survey and my own experience, is not always immediately available; the paediatric senior house officer may not have received any training in resuscitation. Surely this is not acceptable.

Manchester M20 OHL

KF H TEALE

1 Baker M. Enhancing the educational content of SHO posts. BMF 1993;306:808

2 Dubos JP, Cosson M, Truffert P, Morisot C, Rouland V, Kacet $\mathrm{N}$, et al. Development of a training program for neonatal $\mathrm{N}$, et al. Development of a training pro

3 Bailey C. Establishing a neonatal resuscitation team in community hospitals. I Perinatol 1990;10:294-300. 